\title{
Telecommunication Network for Controlling the Processes of Micro-Sized Structures Topology Formation
}

\author{
Ruslan Chkalov ${ }^{1, *}$ \\ ${ }^{1}$ Vladimir State University Named After Alexander and Nikolay Stoletovs, Gorky street, 87, \\ Vladimir, 600000, Russia
}

\begin{abstract}
The article is devoted to the task of organization of complex interaction between separate modules of technological installations for material processing. The basic principles of control software development of industrial laser systems for precision processing, the possibility of implementing remote control of the complex executing hardware are considered. The system application examples for solving problems of highprecision processing of transparent solid materials are shown.
\end{abstract}

\section{Introduction}

Along with the active development of industrial laser systems [1,2], a special position is occupied by high-tech scientific installations aimed at conducting promising fundamental and applied research [3-5]. The gradual development of laser technologies and precision engineering has led to the creation of systems capable of performing precision laser micromachining of materials using femtosecond radiation [6-8].

In connection with the active use of such systems for construction of scientific and experimental complexes, the problem of control software universal package lack arose. Since when working with the installation, the operator primarily deals with the software, the quality of the latter directly determines the effectiveness of the work being done. Thus, the software component is one of the most important parts of any technological system, be it an innovative research facility or a laboratory test bench [9-11].

In accordance with modern requirements for the construction of high-tech laser systems, a precision microprocessing complex was developed, operating under the control of its own software (Fig. 1) [12-14]. The developed installation is characterized by modular design, which makes it a versatile tool for solving a wide range of tasks. The interaction between the control computers and the hardware part of the system is carried out through the TCP/IP protocol, which makes it possible to territorially separate the control and executing components of the system.

\footnotetext{
*Corresponding author: j.larenax@gmail.com
} 


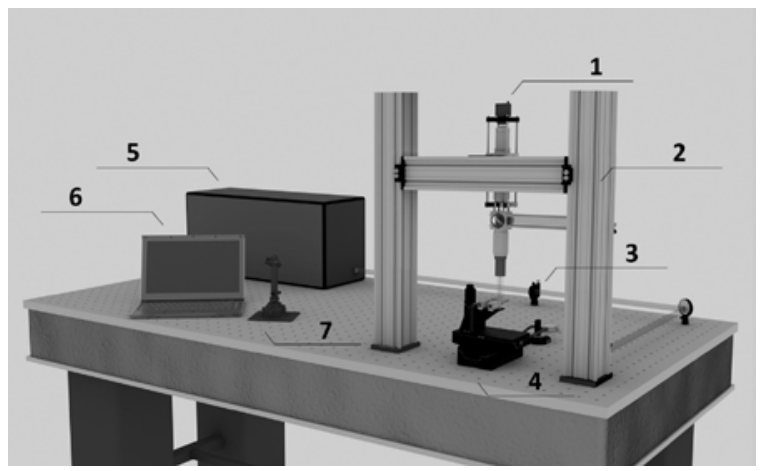

Fig. 1. Femtosecond laser micromachining complex: 1 - camera, 2 - portal periscopic system, 3 variable attenuator, 4 - XYZ-coordinate stages system, 5 - femtosecond laser, 6 - PC, 7 - joystick.

\section{Laser complex control system}

The software of the laser complex is implemented in the object-oriented programming environment Visual C \#, using the Windows Forms API. The connection of the system components is organized according to a modular principle, which also makes it possible to operate a number of third-party technical devices, for example, additional high-speed cameras, optical sensors, etc.

The basic way to control the installation is to form an executable work algorithm by the operator. The command entry window has the basic functionality of any modern code editor, such as syntax highlighting, ability to add comments, functions for quick export and import of command code into text files. When the complex is controlled in the program mode, it is possible to launch a set of commands in a test mode, in which laser radiation will be inactive, in order to preliminary assess correctness of generated code.

Often, if it is necessary to specify complex sequential movements of the coordinate table, the analytical method for constructing the trajectory is inconvenient, since it does not make it possible to evaluate the written code implementation. Alternatively, a visual method for designing the platform movement trajectory in XY plane was formed (Fig. 2).
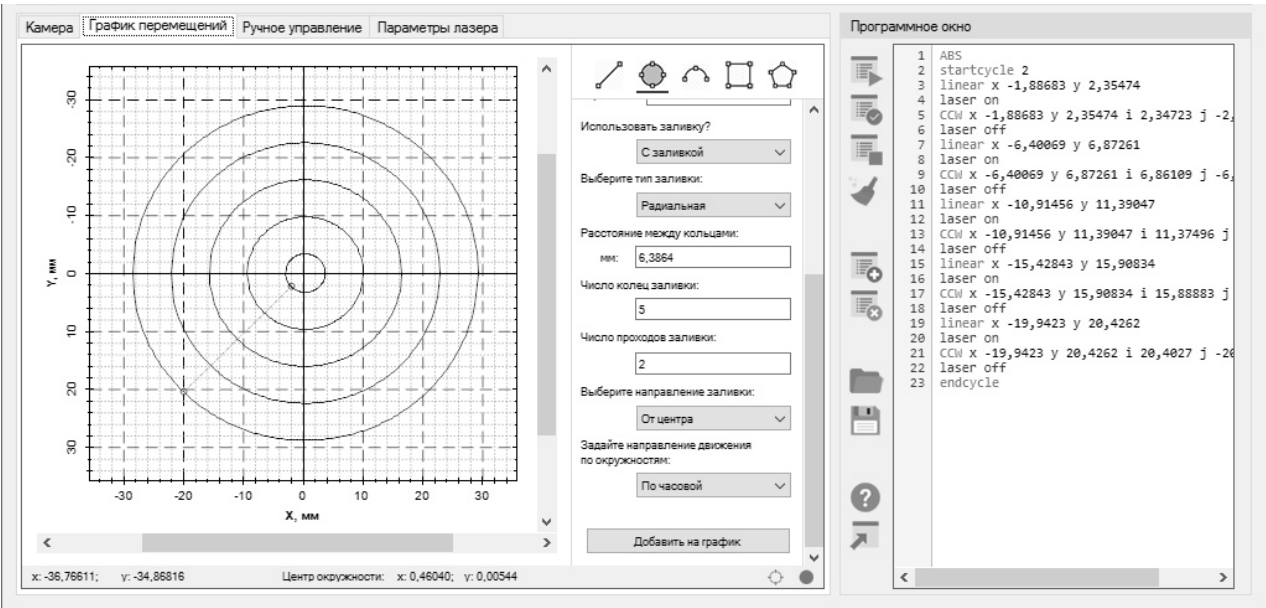

Fig. 2. Developed software graphical interface for the femtosecond laser microprocessing complex. 
The trajectory construction is carried out by sequentially specifying the points of platform/contours movement of graphic primitives on the coordinate plane using a computer mouse, or by filling in a number of key graphs in the corresponding figure section $[15,16]$. This automatically generates the executable code for the command window. So, using the pouring mode when constructing the trajectory allows to form and apply on the sample a lattice of the required size and period (Fig. 3).

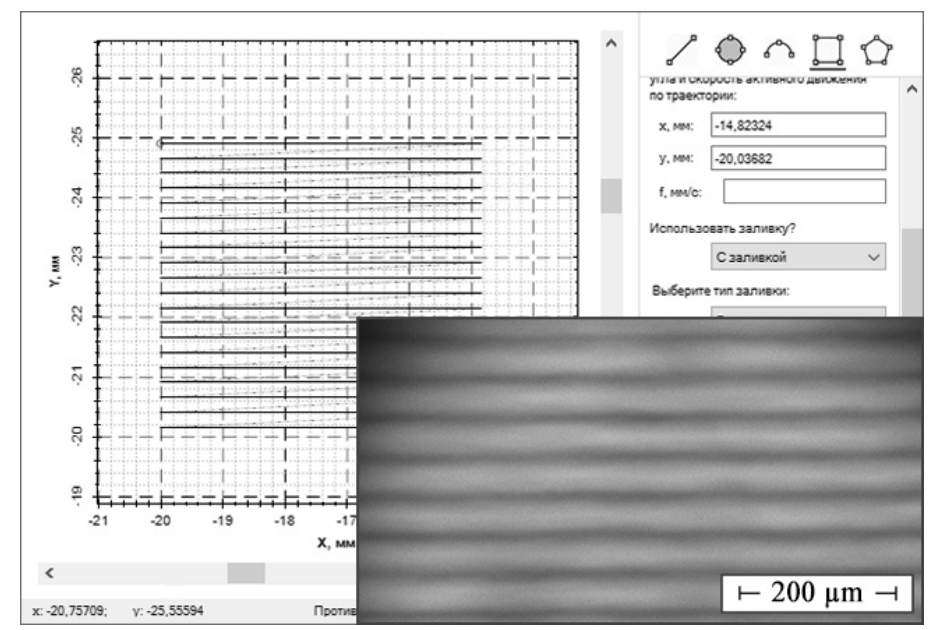

Fig. 3. Using the linear pouring function in the autogeneration mode and a periodic grating applied to a quartz glass sample (inset).

When working with periodic structures [17-19], the ability to change such filling parameters as the density of lines, the speed of movement of the laser beam and the radiation power allows you to quickly carry out a series of experiments in order to select the optimal mode of exposure (Fig. 4).
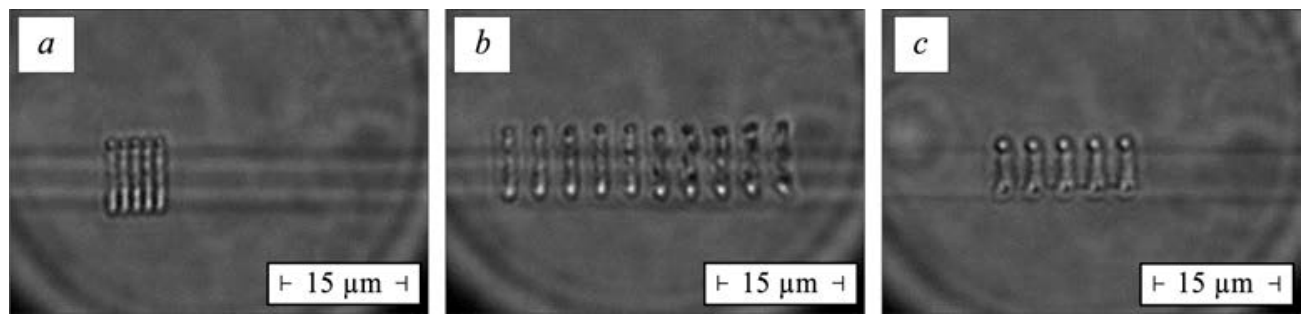

Fig. 4. Waveguide structures recorded in the core of an optical fiber by femtosecond laser radiation: a) radiation power is $5 \mathrm{~mW}$, the passage speed is $50 \mu \mathrm{m} / \mathrm{s}$; b) radiation power $7 \mathrm{~mW}$, passage speed $10 \mu \mathrm{m} / \mathrm{s} ; \mathrm{c}$ ) radiation power $7 \mathrm{~mW}$, passage speed $5 \mu \mathrm{m} / \mathrm{s}$.

\section{Conclusion}

The software that automates the management of complex systems technical components, despite the extremely high demand, is quite rare and highly specialized, as a result of which it is impossible to find a ready-made solution when working with specific high-tech equipment. The development of a software package for the designed hardware laser complex made it possible to organize a unified control system for technical components and nodes of the laser micromachining plant. 


\section{References}

1. B. Schmidt, M. Schaefer, Advanced industrial laser systems and applications, HighPower Laser Materials Processing: Applications, Diagnostics, and Systems VII, v. 10525 (2018)

2. M. Dubois, T.E. Drake Jr, Evolution of industrial laser-ultrasonic systems for the inspection of composites, Nondestruct. Test. Evaluation, v. 26, pp. 213-228 (2011)

3. R.V. Chkalov, D.G. Chkalova, Femtosecond laser micromachining of thin-film coatings in a high-voltage electrostatic field, J. Phys. Conf. Ser., v. 1822 (2021)

4. R. Chkalov, D. Vasilchenkova, Features of thin-film structures formation by direct laser writing method, Mat. Today: Proc., v. 38(4), pp. 1299-1302 (2021)

5. A.S. Chernikov, R.V. Chkalov, D.G. Vasilchenkova, Volume Bragg grating fabrication by femtosecond laser pulses, In 2020 International Conference Laser Optics (2020)

6. R.R. Gattass, E. Mazur, Femtosecond laser micromachining in transparent materials, Nature photonics, v. 2(4), pp. 219-225 (2008)

7. G. Della Valle, R. Osellame, P. Laporta, Micromachining of photonic devices by femtosecond laser pulses, J. Opt. A: Pure Applied Optics, v. 11(1) (2008)

8. K.M. Ahmmed, C. Grambow, A.M. Kietzig, Fabrication of micro/nano structures on metals by femtosecond laser micromachining, Micromachines, v. 5(4), pp. 1219-1253 (2014)

9. B. van Well, S. Murray, et al, An open-path, hand-held laser system for the detection of methane gas, J. Opt. A: Pure Applied Optics, v. 7(6) (2005)

10. L. Peng, Y. Taiping, et al, Direct laser fabrication of nickel alloy samples, Int. J. Mach. Tools Manuf., v. 45(11), pp. 1288-1294 (2005)

11. J.C. Ion, Laser transformation hardening, Surf. Eng., v. 18(1), pp. 14-31 (2002)

12. R. Chkalov, K. Khorkov, V. Prokoshev, Development and application possibilities of multifunctional femtosecond laser complex for precision processing, 2019 International Conference on Industrial Engineering, Applications and Manufacturing (2019)

13. R. Chkalov, K. Khorkov, D. Kochuev, N. Davydov, V. Prokoshev, V. Kostrov, Computerized laser complex for monitoring and controlling of the precision micromachining processes, International Conferences on WWW/INTERNET 2018 and APPLIED COMPUTING 2018, pp. 395-399 (2018)

14. K. Sugioka, Y. Cheng, Femtosecond laser three-dimensional micro- and nanofabrication, Appl. Phys. Rev., v. 1(4) (2014)

15. M. Iqbal, A.P.U. Siahaan, N.E. Purba, D. Purwanto, Prim's algorithm for optimizing fiber optic trajectory planning, Int. J. Sci. Res. Sci. Technol, v. 3(6), pp. 504-509 (2017)

16. X. Wang, W. Sun, et al, Research on trajectory planning of complex curved surface parts by laser cladding remanufacturing, Int. J. Adv. Manuf. Technol., v. 96(5), pp. 2397-2406 (2018)

17. K. Hirao, K. Miura, Writing waveguides and gratings in silica and related materials by a femtosecond laser, Journal of non-crystalline solids, v. 239(1-3), 91-95(1988)

18. K. Miura, J. Qiu, et al, Photowritten optical waveguides in various glasses with ultrashort pulse laser, Appl. Phys. Lett., v. 71(23), pp. 3329-3331 (1987)

19. S.J. Mihailov, D. Grobnic, et al, Extreme environment sensing using femtosecond laser-inscribed fiber Bragg gratings, Sensors, v. 17(12) (2017) 